\title{
A importância da argumentação e da mediação na Educação a Distância e os desafios para a Informática na Educação
}

\author{
Gilda Helena Bernardino de Campos ${ }^{1,2}$, Gianna Oliveira Roque ${ }^{1}$ \\ ${ }^{1}$ Coordenação Central de Educação a distância \\ Pontifícia Universidade Católica do Rio de Janeiro - PUC-Rio \\ ${ }^{2}$ Departamento de Educação - PUC-Rio \\ \{gilda, gianna\}@ccead.puc-rio.br
}

\begin{abstract}
.
The practice of pedagogical mediation in distance courses is a recurring theme in the research on distance learning. Based on the assumption that language is a necessary condition for argumentation, we seek in Habermas, in the Theory of Communicative Action, the basis for the process of mediation. From a longitudinal research carried out in a distance specialization course the results suggest that the mediator can contribute to the student's autonomy and emancipation through the exercise of mutual understanding, assumed as a paradigm that guides the process of pedagogical mediation. This paper aims to discuss the challenges and importance of argumentation and mediation in Distance Learning.
\end{abstract}

Resumo. A prática da mediação pedagógica em cursos a distância é tema recorrente nas pesquisas sobre EaD. Partindo do pressuposto de que a linguagem é condição necessária para a argumentação buscamos em Habermas,na Teoria do Agir Comunicativo, a fundamentação para o processo de mediação. A partir de uma pesquisa longitudinal realizada num curso de especialização a distância os resultados sugerem que o mediador pode contribuir para a autonomia e emancipação do aluno através do exercício do entendimento mútuo, assumido como um paradigma que orienta o processo de mediação pedagógica. Este trabalho tem por objetivo discutir os desafios e a importância da argumentação e da mediação na Educação a Distância.

\section{Introdução}

Algumas questões que vêm sendo aprofundadas pelo Grupo de Pesquisa Cooperação em Educação e Avaliação a Distância do Departamento de Educação da PUC-Rio parecem pertinentes a serem aqui discutidas, pois se relacionam à aprendizagem, à forma na qual aprendemos e como aprendemos, sobretudo quando trabalhamos a distância junto com o professor mediador. Sim, o professor é o mediador da comunidade de aprendizagem que se forma em um curso a distância. Vamos conversar neste artigo sobre a importância da argumentação nos diálogos que se estabelecem nestes cursos e como podemos conduzir os alunos a conquistarem sua autonomia. Diálogos implicam em reciprocidade e, portanto, implicam em uma interatividade que segundo Valle (2012) encontram na educação a distância a possibilidade de uma inversão das atitudes geradas e se confirmaria como um modelo de transformação das arquiteturas pedagógicas uma vez que, entre os 
atores deste processo, é necessário que se estabeleça uma ação comunicativa entendendo este tipo de ação como uma forma de ação social. Habermas afirma que é "nesta forma de ação que o ser humano pode estabelecer uma relação reflexiva com o mundo, possibilitando a coordenação da ação social. Mais do que isto, é no Agir Comunicativo que processos de aprendizagem podem resultar na transformação destes mundos" (BANNELL, 2006).

A abordagem da teoria do Agir Comunicativo (HABERMAS, 2012a) nos parece importante para a discussão da educação uma vez que o conceito de racionalidade comunicativa se vincula ao paradigma do mundo da vida, possibilitando uma "conceitualização do contexto social da vida que se revele adequada aos paradoxos da realidade! " (HABERMAS, 2012a, p.11). Discutiremos a questão do mundo da vida e da Teoria do Agir comunicativo ao longo deste artigo e como a argumentação é estabelecida determinando, em nossa conceituação, a autonomia do aluno.

É possível afirmar que, dentre os principais requisitos para que um país esteja inserido na sociedade da informação, conceito por nós utilizado em oposição à economia do conhecimento, destaca-se a necessidade de uma educação que permita aos indivíduos uma formação de novas habilidades que surgem a partir do século $\mathrm{XX}$, principalmente aquelas voltadas para os usos, apropriações e desenvolvimento das Tecnologias da Informação e Comunicação (TIC). Existem evidências de um consenso entre professores e pesquisadores sobre os ganhos das TICs no processo de ensino e aprendizagem, contudo o grande desafio ainda recai nos usos dessas ferramentas que possibilitem e potencializem a produção do conhecimento e um maior número de incluídos social e digitalmente, não apenas no consumo de informações por meio dessas tecnologias. Neste ponto, ressaltamos que a qualidade de um curso a distância deve recair na dialética que se estabelece entre o professor-aluno-conteúdo e a partir daí na transposição didática realizada através das mídias a serem utilizadas.

\section{O grande desafio: a argumentação}

Para Habermas é por meio da comunicação e da mudança paradigmática da linguagem, cujos pressupostos são o sentido, a argumentação, o consenso, as relações intersubjetivas e o discurso, que se amplia o conceito de racionalidade. Segundo o autor, a racionalidade comunicativa é processual. "É através da comunicação que nós podemos adotar uma relação reflexiva diante do mundo e é essa relação reflexiva que permite uma perspectiva crítica em relação ao mundo" (BANNELL, 2006, p.55). Habermas desenvolve a teoria consensual da verdade, apresentando a verdade do mundo prático, que se apresenta no momento em que garante um processo de aprendizagem entre uns e outros.

(...) os procedimentos argumentativos básicos - que ele identifica como sendo centrais à validação de conhecimento, definido como esquemas interpretativos adequados para o consenso - são fundamentados e se tornam possíveis pela "organização interna da fala" (BANNELL, 2006, p.55).

No livro Teoria do Agir Comunicativo (HABERMAS, 2012a), especificamente na apresentação à edição brasileira, Sbiebeneichler (2012, p. XI) pontua que Habermas "foca seu trabalho analítico tanto na problemática da racionalidade da ação de sujeitos singulares como na racionalização da sociedade em geral". Aponta para duas questões:

Será que processos de modernização da sociedade podem ser analisados sob pontos de vista de uma racionalização e, nesse caso, também sob o 
ângulo crítico de uma racionalização patológica - colonizadora - do mundo da vida moderno por meios sistêmicos? (p. XI)

Gomes (2009) afirma:

A percepção que temos é que, no mundo atual, a Bildung (formação cultural), que poderia proporcionar um sentido emancipatório para a sociedade, encontra-se eclipsada e independentemente desta, sobrepõese hegemonicamente, os projetos educativos que se orientam pela racionalidade cognitivo-instrumental, e que, ao invés de promover a emancipação, conduz a sociedade cada vez mais à alienação e à barbárie (p. 231).

Habermas nos apresenta uma possibilidade de construção recíproca da sociedade, da cultura e da personalidade pelas interações mediadas pela linguagem (BANNELL, 2006, 114). A partir daí, focamos no conceito de racionalidade explicitado na Teoria do Agir Comunicativo, pois relaciona-se com a "aquisição e utilização de saber por parte dos sujeitos providos de competência comunicativa". No prefácio da primeira edição do livro Teoria do Agir Comunicativo, Habermas (2012a) afirma que :

(...) um conceito de racionalidade comunicativa desenvolvido com boa dose de ceticismo, mas mesmo assim resistente às limitações cognitivoinstrumentais impostas pela razão; em seguida, trata-se de um conceito de sociedade em dois níveis, que vincula, de maneira não apenas retórica, os paradigmas "mundo da vida" e "sistema"; por fim, trata-se de uma teoria da modernidade (p.10-11).

O mundo ${ }^{1}$ é constituído de linguagem e há uma conexão entre a função cognitiva e a função comunicativa da linguagem. Para Habermas estabelece-se grande relação entre linguagem e razão, pois a racionalidade comunicativa está localizada na linguagem e é nas práticas linguísticas, onde se potencializa a racionalidade.

Segundo Andrade et al (2016, p.940), essa concepção de linguagem, onde o sujeito aprende a partir da argumentação, mobiliza a crítica a entendimentos prévios, diferencia o certo do errado e busca consenso em meio às diferenças culturais (com respeito às respectivas identidades). Também propõe o diálogo no lugar do conflito, através da interação linguística, entre outros. Essas são capacidades emancipatórias no sujeito, que devem ser assumidas como um objetivo da educação.

Ainda segundo as autoras, por meio da linguagem busca-se o entendimento mútuo através do discurso e das pretensões de validade. "O entendimento mútuo ocorre através da interação dos sujeitos que dialogam entre si, tendo em vista o entendimento, utilizando linguagem inteligível para serem compreendidos" (p. 940). O falante expõe a sua pretensão de validade - sem coação - à análise do outro, que pode aderir ou não, aceitá-la ou não, dependendo da validade dos argumentos proferidos: "isso quer dizer que um ato de fala é bem sucedido na medida em que satisfaz as condições necessárias para o ouvinte assumir uma postura de 'sim' ou 'não' com relação à pretensão de validade levantada pelo falante" (BANNELL, 2013, p. 60).

\footnotetext{
1 Habermas (apud BANNEL, 2013) diferencia o mundo da vida dos subsistemas econômico e administrativo. A esfera privada, familiar e esfera pública compõem o mundo da vida. A educação formal se insere no mundo da vida quando a olhamos nos aspectos político e pedagógico e ao mesmo tempo, é um produto do subsistema econômico e administrativo, já que foi criada para formação de mão de obra e é um aparelho do estado burocrático. A educação formal busca conciliar paradoxos nesse e outros aspectos, e a docência não escapa dessa complexidade.
} 
É nessa possibilidade de crítica e avaliação à pretensão de validade do falante que se constitui a autonomia, a responsabilidade. Se aceitarmos uma pretensão de validade somos corresponsáveis, pois foi uma reflexão própria da racionalidade que levou à adesão (ANDRADE et al, 2016, p.940).

A emancipação do indivíduo se daria, portanto, através da interação comunicativa. Mas para isso, o sujeito precisa ser um "Eu, reflexivo", ou seja, racional e autônomo para participar do discurso.

Todo agente que atue comunicativamente tem que assegurar na execução de qualquer ato de fala, pretensões universais de validade e supor que tais pretensões universais de validade podem desempenharse. Na medida em que queira participar em um processo de entendimento, não pode deixar de assegurar as seguintes pretensões universais de validade: a de estar-se expressando inteligivelmente, a de estar dando a entender algo, a de estar permitindo-se a entender, e a de entender-se com os demais. (HABERMAS, 2001, apud GOMES, 2009, p. 240, grifo do autor).

Essa busca pelo entendimento mútuo é uma ação pretendida pelos envolvidos na construção do conhecimento. Tornar inteligíveis as pretensões de validades é uma exigência ao professor que depende dessa comunicação para conduzir sua mediação, levar o aluno à conclusão do curso, preparado para construir seu trabalho de conclusão com qualidade e agregando valor à área de pesquisa. Mas para isso, há que se reconhecer as relações de poder que permeiam o processo de mediação e o "contexto normativo", que segundo Habermas (2004, p. 117) "explica por que um ator se sente autorizado ou obrigado a determinada ação ou por que ele pode contar com o cumprimento de uma solicitação por parte do destinatário. " Andrade et al (2016) afirmam que, quando compreendido o contexto normativo pelos envolvidos, pode-se aceitar falas reguladoras pelos mesmos motivos e razões. No caso em questão, as falas reguladoras possuem como fim o desenvolvimento de atividades teórico-práticas que consubstanciarão o trabalho científico através da interação virtual entre professor e alunos.

O professor deve buscar através do entendimento mútuo, o verdadeiro consenso, que deve contemplar:

(a) Publicidade e inclusividade: ninguém que pudesse fazer uma contribuição relevante com relação à pretensão de validade controversial deve ser excluído; (b) iguais direitos de se engajar em comunicação: todo mundo deve ter a mesma oportunidade de falar sobre o assunto discutido; (c) exclusão de enganação e ilusão: participantes devem ser sinceros no que eles dizem; e (d) ausência de coerção: a comunicação deve ser livre de restrições que impeçam o melhor argumento a ser levantado e que determinem o resultado da discussão. (HABERMAS, 1999 apud BANNELL, 2013, p. 49).

Habermas (2004) diferencia entendimento mútuo de acordo para tornar claros os dois conceitos. No acordo, os envolvidos "aceitam uma pretensão de validade pelas mesmas razões" (p. 113) e trata-se de uma pretensão de validade universalmente aceitável, e no entendimento mútuo pode haver uma preferência unilateral, uma intenção específica que não é compartilhada por todos os envolvidos, ainda que o ato comunicativo seja inteligível. Como há relações assimétricas dos envolvidos na construção do conhecimento no decorrer de um curso, ocupando papéis distintos, com vinculação distinta na instituição e no envolvimento com o trabalho, compreendemos que o conceito 
de entendimento mútuo representa melhor esta relação e o encadeamento dos atos de fala dos sujeitos (ANDRADE et al, 2016, p.942).

\section{Confirmando o desafio}

Em recente pesquisa com 2138 respondentes, alunos de pós-graduação lato sensu, questionamos a respeito do professor atuando como mediador pedagógico. Os resultados das análises estatísticas realizadas nos mostraram que é possível não só categorizar as respostas dos alunos como estas apontam para a questão da autonomia e emancipação explicitada por Habermas, como veremos a seguir.

Ao examinarmos a Tabela 1, que apresenta o resultado do teste de fidedignidade do questionário, verificamos que a variável latente "Mediador" já se destacava como sendo a mais fidedigna, com Alfa de Cronbach .96, muito acima do resultado das demais variáveis, todas abaixo de .90 .

Tabela 1. Fidedignidade das subescalas

\begin{tabular}{|l|c|c|}
\hline \multicolumn{1}{|c|}{ Variáveis Latentes } & $\mathrm{A}$ & $\begin{array}{c}\text { Número de } \\
\text { Indicadores }\end{array}$ \\
\hline Conteúdo & .85 & 5 \\
\hline Tarefa & .81 & 5 \\
\hline Ferramentas de Comunicação & .88 & 6 \\
\hline Mediador & $\mathbf{. 9 6}$ & $\mathbf{9}$ \\
\hline Ambiente & .89 & 8 \\
\hline Auto-avaliação & .81 & 4 \\
\hline & $(\mathrm{N}=2.138)$ \\
\hline
\end{tabular}

Em relação à opinião dos cursistas sobre a atuação do mediador pedagógico, verificamos uma excelente aprovação dos alunos na forma na qual os mediadores desenvolveram seu trabalho. Essa aprovação está refletida na curva totalmente e positivamente assimétrica, obtida a partir da análise de todas as questões que compreenderam a variável "Mediador", e citamos algumas: (a) O mediador pedagógico domina o conteúdo da matéria das disciplinas; (b) $\mathrm{O}$ mediador pedagógico manteve sempre um bom relacionamento com os cursistas; (c) Todas as discussões promovidas no curso foram acompanhadas pelo mediador pedagógico, que participou e esclareceu as dúvidas que surgiram; (d) O mediador pedagógico trouxe para o curso assuntos de cunho geral (do dia-a-dia) relacionados ao conteúdo da matéria; (e) Houve comprometimento por parte do mediador pedagógico com a qualidade do curso.

Os depoimentos dos alunos mostraram desdobramentos efetivos em sua prática profissional. A mediação pedagógica mostrou que, ao provocar o ato de reflexão nos alunos, pode, também, promover a transformação de sua atuação em sala de aula, sua formação e desenvolvimento profissional. A reflexão conduzindo à possibilidade da argumentação provocou a necessidade da autonomia do aluno refletindo em seu desenvolvimento profissional. No processo de desenvolvimento do curso foi possível perceber que a mediação pedagógica aparecia como uma atividade permanente e individualizada, para acompanhar os alunos e oferecer a cada um o auxílio necessário à crítica e avaliação a pretensão de validade do falante em algum específico contexto. Logicamente, seria possível discutirmos as diferentes formas que a mediação pedagógica assume, mas cremos que a mediação está diretamente relacionada ao professor e ao aluno. 
Nesta díade que se estabelece é possível compreender a busca da autonomia e, em última análise, o ofício do professor. $\mathrm{Na}$ análise dos componentes principais das respostas obtidas ao questionário foi possível perceber que apenas dois componentes foram suficientes para explicar a variância, e que os itens mais relacionados com a variável sintética "Mediador" são justamente os itens de maior correlação com o primeiro componente principal. O exame das linhas iniciais da análise estatística indicou que são todas ocupadas por indicadores ou itens referentes ao professor mediador do curso.

\section{Comentários Finais}

Como conclusão da análise realizada, ressaltamos que para os alunos o mediador pedagógico é de fundamental importância a fim de que o curso obtenha sucesso, no entanto, percebemos a dificuldade de reconstrução da prática do professor. Prado e Silva (2009) ressaltam, citando outros autores, que o conhecimento adquirido pelo professor durante o curso de formação precisa ser recontextualizado na sua prática pedagógica. "A recontextualização implica integrar os diferentes recursos tecnológicos aos conteúdos curriculares e dar vida às teorias educacionais na realidade da escola" (p.63).

Dentre todas as competências exigidas ao longo do processo de mediação, quatro delas se destacam por permearem todas as demais e, citamos: atenção, clareza, visão sistêmica e resiliência. Elas são competências complementares e, cada uma é fundamental para que as demais possam fluir de forma natural. Coelho (2011) ressalta que Habermas não trata da prática pedagógica na escola ou no Ensino Superior mas seu pensamento pode ser utilizado indiretamente "se levarmos em conta o modelo de racionalidade proposto" (p.91). Ressalta, a partir da pragmática da linguagem algumas "características, atributos ou predisposições que contribuem para uma racionalidade intersubjetiva, tais como: paciência, clareza na exposição, gentileza, perspicácia, capacidade de saber ouvir o outro e incluí-lo no debate, atenção à ambiguidade sempre presente na língua corrente e à falta de clareza dos termos (p.92). Percebemos exatamente estas características não só na "fala" dos alunos como também na literatura consultada. Algumas questões se entrelaçam ainda a partir dos resultados, a saber: Será que as ferramentas nos ambientes de aprendizagem on-line são suficientes para garantir a argumentação? A formação dos professores é adequada à mediação no sentido proposto por Habermas?

Outras questões surgem quando pensamos nos modelos de educação a distância que vemos no país, com turmas gigantescas para um único professor mediador. A partir da dificuldade em garantir a argumentação nesse tipo de turmas, novas ferramentas tem sido implementadas como o FAT, (F)orum (A)ssessment (T)ool, uma ferramenta que auxilia os mediadores, em tempo real, à avaliação das discussões no fórum, utilizando tecnologia semântica e métodos estatísticos que buscam, expõe e recomendam tópicos relevantes que foram discutidos e devem ser aprofundados pelo mediador (NUNES et al., 2015). Outro exemplo é o Highlight, uma ferramenta que apoia os alunos na aprendizagem dos conteúdos em EaD (NUNES et al., 2011). Ainda apontamos para o desafio de formar os mediadores para uso destas novas ferramentas que devem ser desenvolvidas para atender às necessidades dos alunos a fim de possibilitar a real argumentação dos mediadores.

\section{Referências bibliográficas}

ANDRADE, J. Z. ; SILVA, E. C. ; MELO, K. S. ; ROQUE, G. O. B. ; CAMPOS, G. H. B. . Construindo a Mediação a partir do Conceito de Entendimento Mútuo em Habermas. In: IV Congresso TIC e Educação, 2016, Lisboa. IV Congresso TIC e Educação, 2016. 
BANNELL, Ralph. I. Teoria do Agir Comunicativo: Esfera pública e a formação da opinião pública. Trabalho apresentado no $2^{\circ}$. Seminário Internacional de pesquisa em Comunicação. Programa de Pós-graduação em Comunicação social. UFSM, 2006.

. Habermas \& a educação. 2ª . Ed. Belo Horizonte. Autêntica Editora, 2013.

CAMPOS, G. H. B. de; ZIVIANI, C.; ROQUE, G. O. B. Análise da Avaliação da Qualidade em Educação a Distância no Modo 2 da Produção do Conhecimento. Revista e-Curriculum, São Paulo, v.11 n.01 abr.2013. pp. 181-200. Disponível em http://revistas.pucsp.br/index.php/curriculum/article/view/9320/11306.

COELHO, M. B. Qualidade Argumentativa: Uma Competência Política na Esfera Pública. In: Ralph Ings Bannell; Rita Vilanova; Claudia Fenerich.. (Org.). A Formação para a Cidadania e os Limites do Liberalismo. Rio de Janeiro: 7 Letras. 2011.

GOMES, L.R. Educação e Comunicação em Habermas: o entendimento como mecanismo de coordenação da ação pedagógica. Cadernos de Educação. Pelotas, [33].

Retirado

de: https://periodicos.ufpel.edu.br/ojs2/index.php/caduc/article/viewFile/1659/1542 2009

HABERMAS, Jürgen. Verdade e Justificação: ensaios filosóficos. Edições Loyola, São Paulo, 2004.

Teoria do Agir Comunicativo 1: Racionalidade da ação e racionalização social. Tradução: Paulo Astor Soethe. São Paulo: Editora WMF Martins Fontes, 2012a.

Teoria do Agir Comunicativo 2: sobre a crítica da razão funcionalista. Tradução: Flávio Beno Siebeneichler. São Paulo: Editora WMF Martins Fontes, 2012b.

NUNES, B. P.; SCHOTTLER, A. ; Feliciano, L. ; CAMPOS, G. H. B. . Highlight: A support tool in distance education courses. In: International Conference and Advanced Technology in Education - ICCATE 2011, 2011, Beijing. International Conference and Advanced Technology in Education, 2011.

NUNES, B. P.; TYLER-JONES, M. ; CAMPOS, G. H. B. ; SIQUEIRA, S. W. M. ; CASANOVA, Marco A. . FAT: A real-time (F)orum (A)ssessment (T)ool to assist tutors with discussion forums assessment. In: The 30th ACM/SIGAPP Symposium On Applied Computing, 2015, Salamanca. SAC 2015: Symposium on Applied Computing Proceedings, 2015.

PRADO, M. E.B., SILVA, M. G. M.. Formação de educadores em ambientes virtuais de aprendizagem. In, Em Aberto, Brasilia, v.22,n.79,p.47-74,jan.2009

ROQUE, G. O. ; Campos, G. H. B. ; SANTOS, C. S. . Quality in Distance Learning Courses: A longitudinal survey of teacher training in federal programs. In: Susan Zvacek;Maria Teresa Restivo; James Uhomoibhi;Markus Helfert. (Org.). Quality in Distance Learning Courses: A Longitudinal Survey of Teacher Training in Federal Programs. 1ed.Switzerland: Springer International Publishing Switzerland, 2015, v. 583 , p. 241-255.

VALLE, L. do; BOHADANA, E. Interação e Interatividade: por uma reantropolização da EaD Online. Educ. Soc., Campinas, v. 33, n. 121, p. 973-984, out.-dez. 2012. Disponível em http://www.cedes.unicamp.br. 